\title{
Assembly and Irradiation Modeling of Residual Stresses in Low-Enriched Uranium Foil-Based Annular Targets for Molybdenum-99 Production
}

\author{
Srisharan G. Govindarajan, Brian S. Graybill, Philip F. Makarewicz, \\ Zhentao Xie, and Gary L. Solbrekken \\ Department of Mechanical and Aerospace Engineering, University of Missouri, E2413 Lafferre Hall, Columbia, MO 65211, USA \\ Correspondence should be addressed to Srisharan G. Govindarajan; sgkff@mail.missouri.edu
}

Received 31 May 2013; Accepted 29 August 2013

Academic Editor: George Vandegrift

Copyright (C) 2013 Srisharan G. Govindarajan et al. This is an open access article distributed under the Creative Commons Attribution License, which permits unrestricted use, distribution, and reproduction in any medium, provided the original work is properly cited.

\begin{abstract}
This paper considers a composite cylindrical structure, with low-enriched uranium (LEU) foil enclosed between two aluminum 6061-T6 cylinders. A recess is cut all around the outer circumference of the inner tube to accommodate the LEU foil of open-cross section. To obtain perfect contact at the interfaces of the foil and the tubes, an internal pressure is applied to the inner tube, thereby plastically and elastically deforming it. The residual stresses resulting from the assembly process are used along with a thermal stress model to predict the stress margins in the cladding during irradiation. The whole process was simulated as a steady-state two-dimensional problem using the commercial finite element code Abaqus FEA. The irradiation behavior of the annular target has been presented, and the effect of the assembly residual stresses has been discussed.
\end{abstract}

\section{Introduction}

The majority of the molybdenum-99 (Mo-99) produced internationally is extracted from high-enriched uranium (HEU) dispersion targets that have been irradiated. Mo-99 is the parent isotope of the radioactive tracer, technetium$99 \mathrm{~m}$, which is used in medical imaging procedures. The high concentration U-235 in HEU-based targets makes them potential items of interest for rogue individuals. To alleviate the potential of proliferation issues, low-enriched uranium (LEU) targets are being mandated. Unfortunately the conversion of HEU- to LEU- based dispersion targets is accompanied by a reduction in Mo-99 production given today's dispersion target technology. An increase in the density of uranium is needed in LEU-based targets in order to recover the loss in Mo-99 production per target [1]. One strategy to increase the uranium density is to use an LEU metal foil placed within the 6061-T6 aluminum cladding [2]. A second advantage of the LEU foil-based target is that it allows for the potential of the LEU foil to be removed after irradiation so that it can be dissolved by itself, reducing the liquid waste that would be generated by dissolving the entire target, including the 6061-T6 aluminum cladding. In this paper the aluminum 6061-T6 cladding will be simply referred to as "aluminum cladding."

The function of the target is to contain the fission products and to effectively dissipate the generated fission heat to the reactor coolant. For dispersion target designs there is generally little concern about heat getting dissipated to the coolant as the target structure offers little resistance to heat transfer. However, for the disassemble-able LEU foil target; there is a potential of the cladding to separate from the LEU foil and significantly increase the thermal resistance between the LEU and cladding. The increase in thermal resistance could lead to a rise in LEU temperature that might exceed the limits set forth by the reactor. An analysis needs to be conducted on this target structure to ensure safe usage both during assembly and irradiation.

The target is assembled by wrapping a thin nickel foil $(\sim 15 \mu \mathrm{m})$ around the LEU foil and placing it on the outer 
circumference of the inner aluminum tube. The width of the foil is such that it does not wrap all the way around the inner tube, leaving a gap, as illustrated in Figure 1. The gap provides a cutting street for postirradiation disassembly of the target. An aluminum outer tube is slid over the inner tube and the Ni-wrapped LEU foil. The nickel acts as a recoil barrier to prevent the LEU foil from bonding with the cladding, while aluminum is used as the cladding material due to its small neutron absorption cross-section [3].

An internal pressure is applied to the inner surface of the inner tube to close the gap between the foil and the outer tube. The internal pressure can be applied by either a draw plug or by using a pressurized hydraulic fluid [4]. The internal pressure applied to the inner cylinder causes it to expand and plastically deforms it. The magnitude of the required internal pressure is calculated by applying the condition that at the end of the process the LEU foil and the outer tube share a common interface. This assembly process creates a sandwiched structure where the interfaces between all the target components are in contact with one another.

By design, the assembly process leaves residual stresses in the aluminum cladding. Previous thermal-mechanical analysis on annular targets with zero residual stresses has shown that there is a tendency for a gap to open up between the foil and the outer tube [2]. Hence, it is important to model the irradiation process by including the assembly residual stresses and to design the assembly process such that the residual stresses help prevent any gaps from forming. It has been shown that based on the direction of heat flow in a sandwich cylinder, contact can be established or withdrawn [5]. Though these annular targets have been safely irradiated in the past [6], the magnitude of the resulting thermal stresses is unknown. This paper will seek to establish, by means of numerical analysis, the thermal stress margins in these annular targets by including the residual stresses from the assembly process.

\section{Numerical Model}

A numerical model of the annular target assembly was created using the commercial finite element code Abaqus FEA [7]. A three-step analysis was created to model the assembly of the tubes, the residual stresses, and the irradiation process. In the first step, the hydroforming assembly process is simulated by the application of a calculated internal fluid pressure. The second step is a zero pressure step, where the applied internal pressure is removed and the target is allowed to relax. Any remaining stresses in the target are the residual stresses that will help to keep gaps from forming between the LEU and cladding. The final step simulated is the irradiation heat generating process. This step is simulated by applying a volumetric heat generation rate to the LEU foil.

The finite element mesh used in the analysis, consisting of 16000 elements and 51221 nodes with 10 elements through the thickness of each assembly component, is illustrated in Figure 2. Thus, the final assembly consisted of 30 elements through all the components. It is important to note that the assembly and the residual stress part were modeled as a

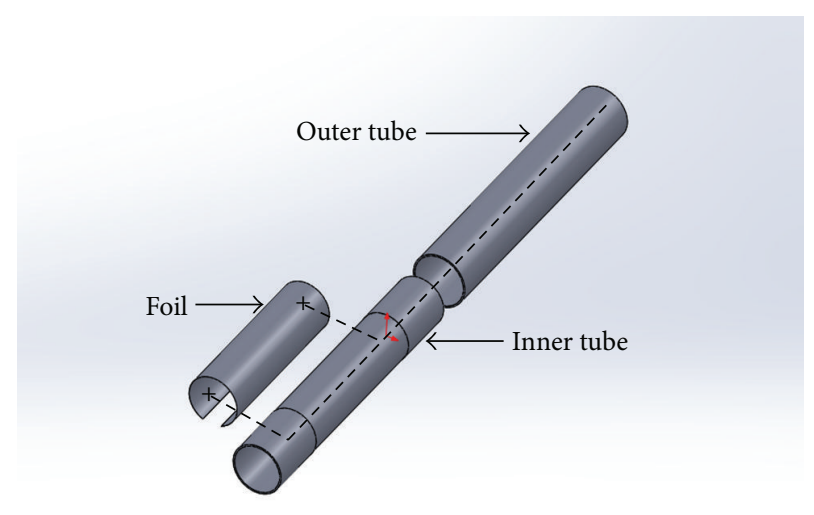

FIGURE 1: Exploded view of the target assembly.

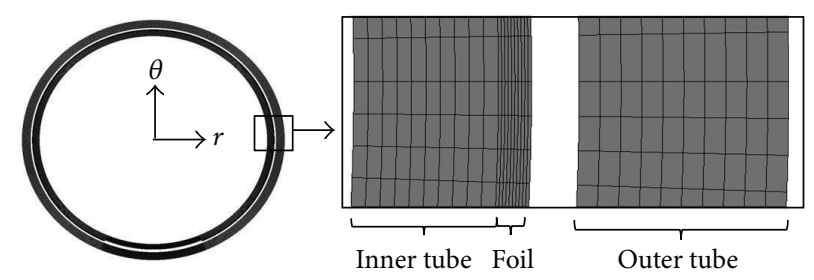

FIGURE 2: Finite element mesh used in the three-step analysis.

fully coupled thermal stress problem instead of a static stress analysis. This makes it easier to add a third step to run the irradiation analysis. If a static stress analysis type is used for the first two steps, an Abaqus script file is required to input the residual stress data into the irradiation model which uses a fully coupled thermal stress step. Fully coupled quadratic reduced integration elements of type CPE8RT were used in the analysis.

2.1. Assembly and Residual Stress Model. The development of the assembly model follows directly from the Argonne National Lab (ANL) target design [6]. Since the mechanical model was constructed in two dimensions, the relevant crosssectional area of the target occurs at the midpoint of the target's length, such that the inner tube, outer tube, and uranium foil are all present in the model, as illustrated in Figure 3.

As the model is based on the ANL target, all the tube dimensions are precisely those described by the technical drawing of that target. Again, because the cross-section occurs at a length along the target that includes the uranium foil, the dimensions of the inner tube correspond to the ANL foil relief specifications. In addition, it should be noted that the foil is assumed to be in perfect initial contact with the inner tube. While this is not necessarily the case with physical specimens, it is an essential simplification to the model. The assembled stress state of a target is important as it can either aid or hinder the disassembly process. In order to achieve a stress state that encourages the target to open after being cut longitudinally, the inner tube must be plastically deformed and the outer tube must be only elastically deformed. To 


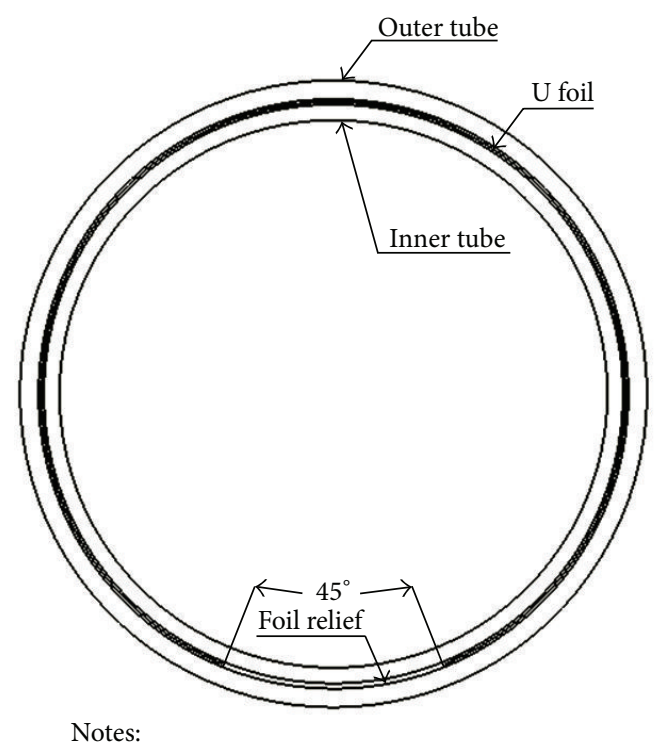

(1) Foil thickness: $125 \mu \mathrm{m}$

(2) Inner tube ID: $26.210 \mathrm{~mm}$

(3) Inner tube OD: $27.714 \mathrm{~mm}$

(4) Outer tube ID: $28.220 \mathrm{~mm}$

(5) Outer tube OD: $30.000 \mathrm{~mm}$

Figure 3: Drawing of the geometry used for the assembly model in the first analysis step.

simulate plastic deformation, a plastic material model must be defined within Abaqus. This data must be given in the form of true stress and plastic strain. In some cases, it may be necessary to convert engineering stress and strain to true stress and plastic strain. However, as the tube material being investigated at the University of Missouri-Columbia is Al 6061-T6, the true stress and plastic strain data for aluminum 6061-T6 was obtained from [8], while the flow curve equation based on [9] was used to construct the true stress versus plastic strain curve for uranium as illustrated in Figure 4.

The plasticity data supplied by [9] is in the form of strength coefficients and hardening exponents, $K$ and $n$. For unalloyed uranium, the alloy used in this study, $K$ and $n$, is $1.14 \mathrm{GPa}$ and 0.23 , respectively. These values are used in the plastic flow equation given by the following:

$$
\sigma=K \varepsilon^{n}
$$

where $\sigma$ is true stress and $\varepsilon$ is plastic strain. It should be noted that according to [9] the values of the strength coefficient and strain hardening exponent are only valid for plastic strains between 0.001 and 0.01 . The elastic material definitions are much simpler to create, requiring only the elastic modulus and Poisson's ratio. For the aluminum tubes, the values used were $68.9 \mathrm{GPa}$ and 0.33 , respectively. The elastic modulus for uranium used was $208 \mathrm{GPa}$, and Poisson's ratio was 0.23 (typical for unalloyed metals).

The desired internal pressure for hydroforming was determined through a combined analytical and experimental approach. According to analytical plastic theory, the critical pressure which will cause yielding is given by the following as

$$
P=\frac{\sigma_{o}}{2}\left(\frac{b^{2} / a^{2}-1}{b^{2} / r^{2}}\right)
$$

where $P$ is the critical pressure, $\sigma_{o}$ is the yield stress, $b$ is the outer diameter of a cylinder, and $r$ is the location of interest through the cylinder wall. Assuming $r$ to be the inner diameter $(r=a)$ reduces (2) to

$$
P=\frac{\sigma_{o}}{2}\left(1-\frac{a^{2}}{2 b^{2}}\right) .
$$

Using the dimensions of the inner tube previously described and a typical yield stress for Al 6061-T6 of $255 \mathrm{MPa}$, the calculated critical pressure using (3) is $13.75 \mathrm{MPa}$. This is the pressure that will initiate yielding in the inner tube. The corresponding displacement for the critical pressure is determined. A parametric study is performed to determine the pressure that will nearly close the gap between the foil and the outer tube and is found to be $16.3 \mathrm{MPa}$. However, this 16.3 MPa does not induce enough plastic deformation to keep the gap closed after unloading. After analytically determining the proper order for internal pressure, several tests were conducted to precisely determine the internal pressure required to close the gap. This was accomplished using a hydroforming test bench developed at the University of Missouri. Hydroforming provides an advantageous testing method because only the internal pressure is required to assemble the target.

Through the experiments run with the hydroforming test bench (Figure 5), the maximum allowable pressure (i.e., the maximum pressure that does not rupture the target) was determined to be $36.4 \mathrm{MPa}$. Thus, the internal pressure applied to the Abaqus model in the assembly step was 36.4 MPa as illustrated in Figure 6. It should be noted that above this pressure, the targets ruptured, with both the inner and outer tubes splitting along the longitudinal relief where the inner and outer tubes were in direct contact, without uranium in between. The application of the internal pressure only constitutes the first step of the multistep model. Simulation of the assembly requires the addition of a step in which the internal pressure is returned to zero. There are two purposes for the pressure relaxation step. First, this simulates the actual target assembly process: an internal pressure is applied to assemble the tube and foil and then removed in order to remove the target from the hydroforming rig. Because, at the applied pressures, the outer tube is not plastically deformed, there is some elastic recovery upon removal of the internal pressure. The remaining stresses in the target are known as residual stresses, leading to the second purpose for simulating the pressure relaxation. The residual stresses are of interest in the assembly process as the residual state can either aid or hinder the disassembly process. If tensile stresses remain in the outer tube, it will "spring" open when cut along the longitudinal relief for retrieval of the uranium foil. However, compressive residual stresses will cause the outer tube to collapse, increasing the time and 


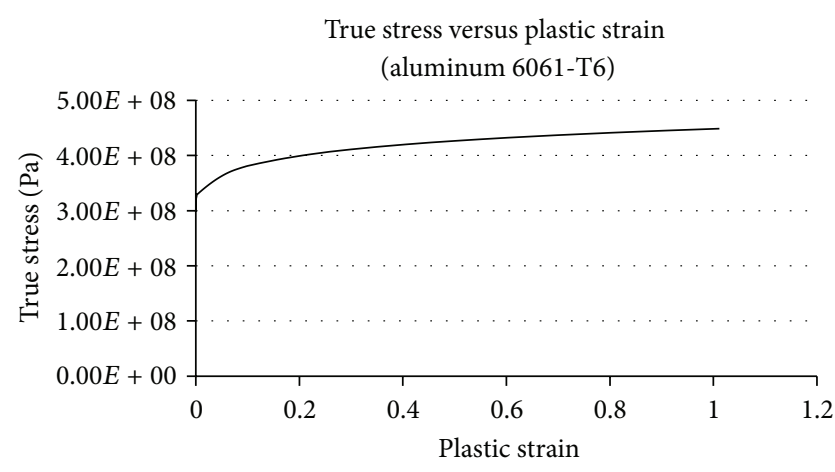

(a)

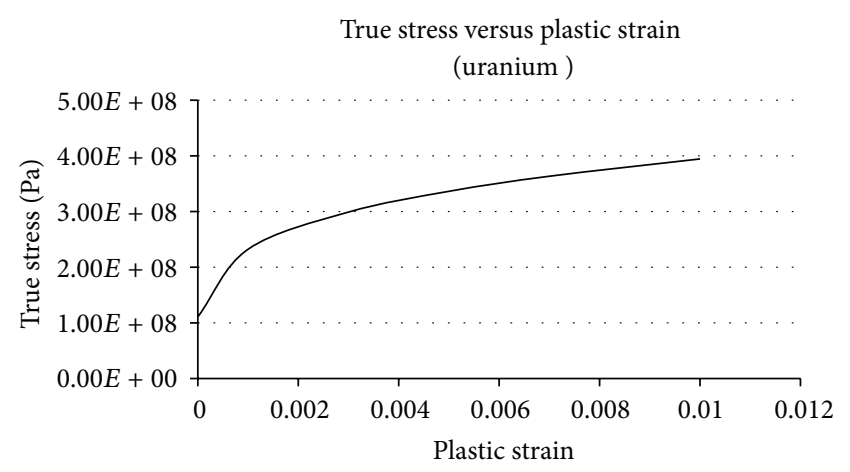

(b)

FIGURE 4: True stress and plastic strain data for aluminum 6061-T6 and uranium.

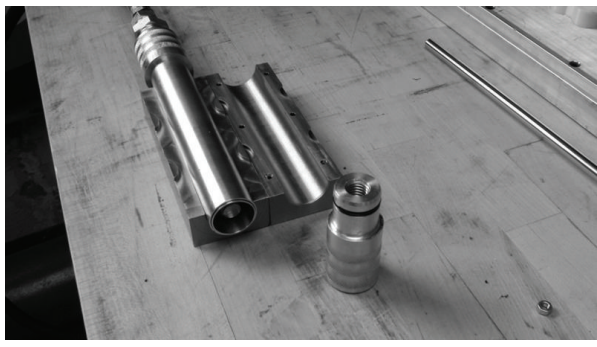

(a)

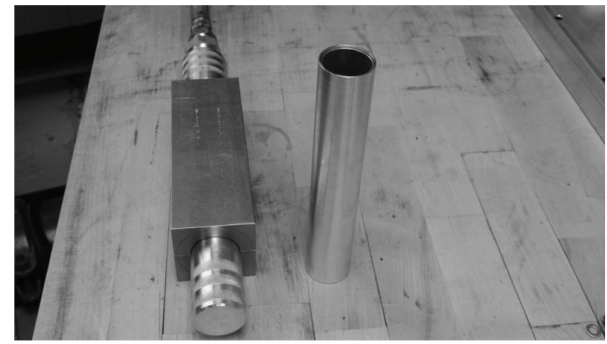

(b)

FIgURE 5: (a) Hydroforming test rig with annular target in place. (b) Assembled hydroforming test rig.

effort required to remove the irradiated foil from the target. Thus, the simulation of pressure relaxation serves to verify a favorable residual stress state, improving production.

2.2. Irradiation Model. To model the irradiation behavior which takes into account the residual stresses from the assembly process, a fully coupled thermal stress step was added after the residual stress step. The loading conditions and the contact definitions from the first two steps were suppressed. A heat generation rate of $1.6 \times 10^{10} \mathrm{~W} / \mathrm{m}^{3}$ was applied to the foil, which corresponds to a heat flux of $100 \mathrm{~W} / \mathrm{cm}^{2}$ incident on the outer surface of the inner tube and the inner surface of the outer tube. Water coolant flow at $323 \mathrm{~K}$ through the inner and along the outer tubes was simulated by defining a surface heat transfer coefficient and a sink temperature. The heat transfer coefficient of $19000 \mathrm{~W} / \mathrm{m}^{2} \mathrm{~K}$ corresponds to a flow velocity of $0.83 \mathrm{~m} / \mathrm{s}$ through the inner tube and $1.86 \mathrm{~m} / \mathrm{s}$ along the outer tube. The loading and boundary conditions for the irradiation model are illustrated in Figure 7.

New contact definitions had to be made for the irradiation model due to the different contact interaction property for the normal behavior. For the irradiation model it is assumed that the tubes may have a tendency to separate after they come in contact, whereas for the hydroforming part, the normal behavior does not allow any separation once the tubes are in contact. This is the main difference in the mechanical contact definition properties for the assembly and the irradiation part. Due to the composite structure of the model and the presence of interfaces, a thermal conductance had to be defined while defining the contact interaction properties. As the magnitude of the thermal conductance is unknown, an infinite conductance was specified at zero clearance, and for a clearance of $0.01 \mathrm{~m}$ the thermal conductance is assumed to be zero. Abaqus interpolates between these values to obtain the thermal conductance for any interfacial gap in the model. It is assumed that there is conduction through the air, and the effects of heat redistribution have not been considered in modeling the gap.

\section{Results}

Figure 8 illustrates the displacement contour after the first assembly step, which simulates the hydroforming process. Though the applied internal pressure closes the gap between the foil and the outer tube, a gap $(\sim 200 \mu \mathrm{m})$ still remains close to the edges of the foil, in the region between the inner and the outer tubes. The maximum displacement occurs in the inner tube at $180^{\circ}$ as illustrated in Figure 8.

Figure 9 illustrates the equivalent plastic strain across the thickness of the annular target assembly. The Abaqus parameter name for this is "PEEQ" and is used to evaluate the yield condition. For isotropic hardening and Von Mises plasticity, PEEQ is defined as $\sqrt{(2 / 3) d \varepsilon^{\mathrm{pl}}: d \varepsilon^{\mathrm{p}}}$. It is essentially a scalar measure of all components of equivalent plastic strain in a model, and a value of PEEQ greater than zero 


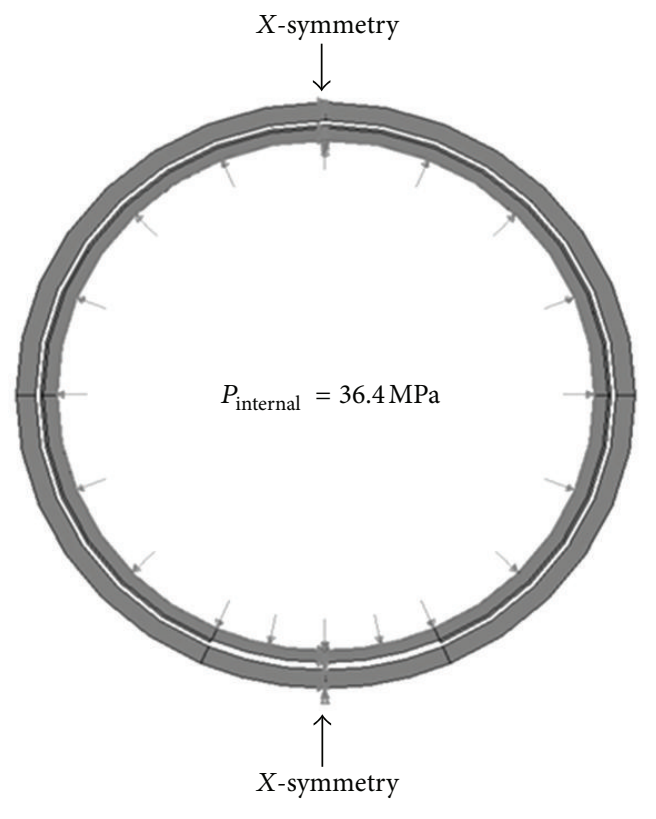

$X$-symmetry: $U 1=0$ (no translation in radial direction)

$U R 2=0$ (no rotation in the " $\theta$ " direction)

FIGURE 6: Loading and boundary conditions for the hydroforming model in the first analysis step.

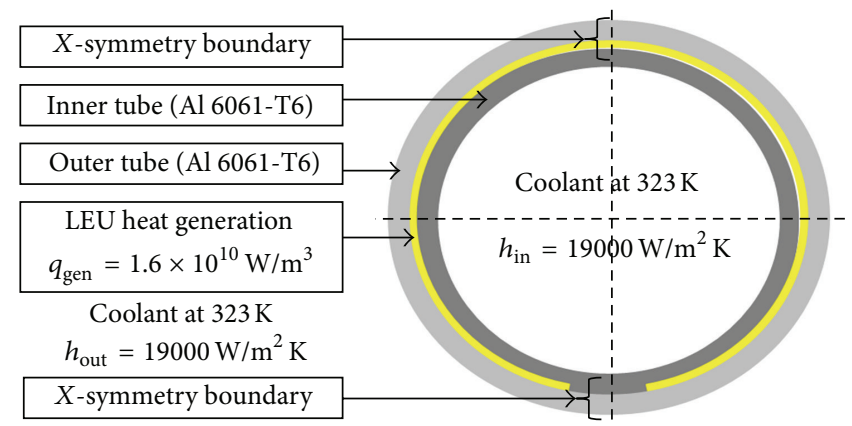

FIGURE 7: Loading and boundary conditions for the irradiation model in the third analysis step.

indicates that the material has already yielded. As expected, the combined effects of heating and assembly stresses result in a higher plastic strain at the end of the irradiation step than in the previous steps. Also, the plastic strain remains the same during the pressure relaxation step. This is because, when the applied load is removed the inner tube elastically recovers, but the plastic deformation due to the hydroforming process remains in the inner tube. Figure 9 also illustrates the plastic deformation in the outer tube. For the irradiation step, there is a small amount of plastic deformation in the outer tube, while there is zero plastic deformation in the outer tube for the first two steps. This means that the plastic deformation in the outer tube at the end of the irradiation step is purely due to thermal effects.

One of the goals of the hydroforming process is to close the gap between the foil and the outer tube by plastically deforming the inner tube. The magnitude of the applied hydroforming pressure should be such that it should be able to close the gap between the foil and the outer tube and induce sufficient plastic deformation in the inner tube so that even during elastic recovery an interfacial bond is maintained between the foil and the outer tube. Figure 10 illustrates the separation between the outer tube and the foil. For the hydroforming and the pressure relaxation step there is zero separation. This means that the applied hydroforming pressure of 36.4 MPa is sufficient to maintain the contact between the foil and the outer tube when elastic recovery occurs. However, a gap does open up during the irradiation step due to thermal expansion mismatch and radially outward heat flow.

Figure 11 illustrates the radial temperature distribution in the inner tube and outer tube cladding. The temperature 


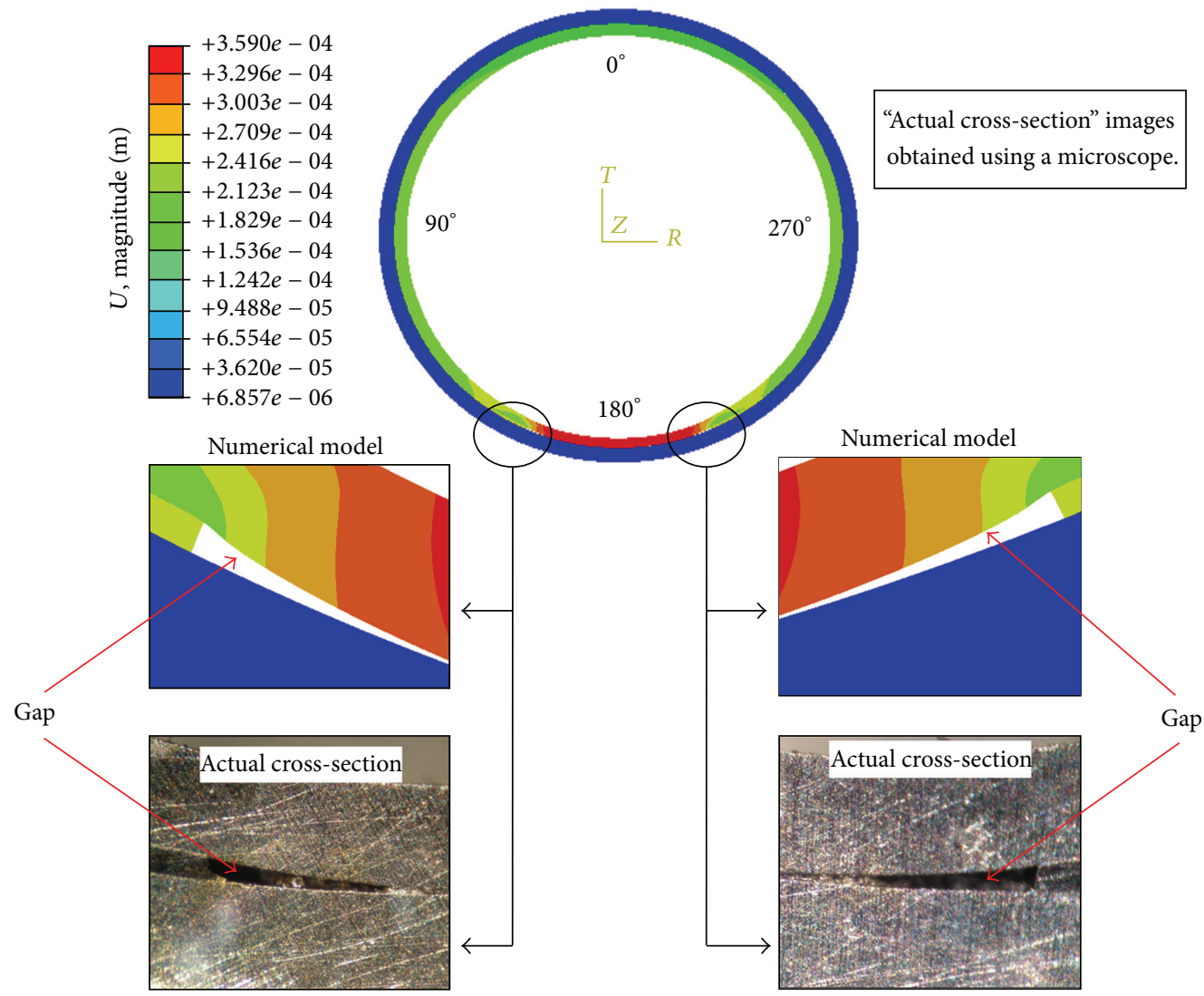

Figure 8: Postassembly numerical displacement contour and microscope images.

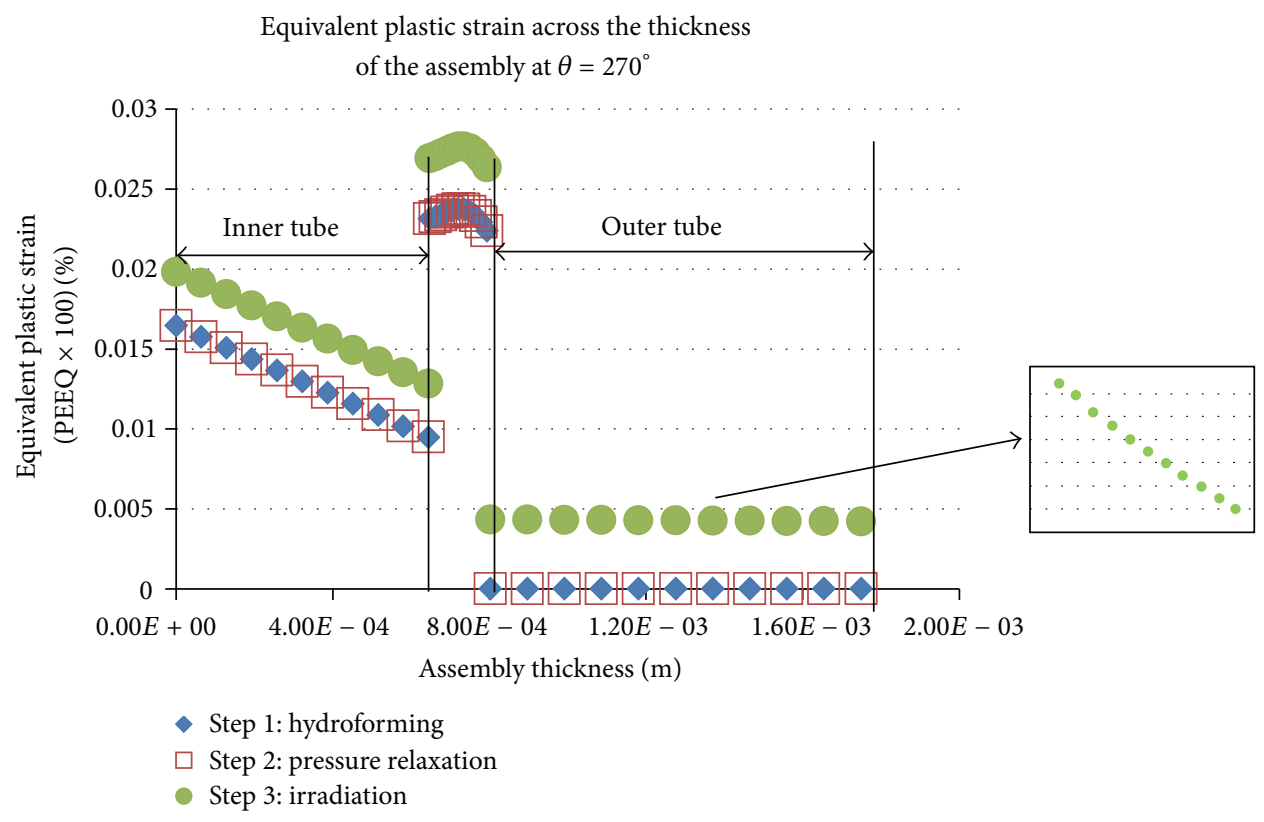

FIGURE 9: Equivalent plastic strain across the assembly radius at $\theta=270^{\circ}$. 


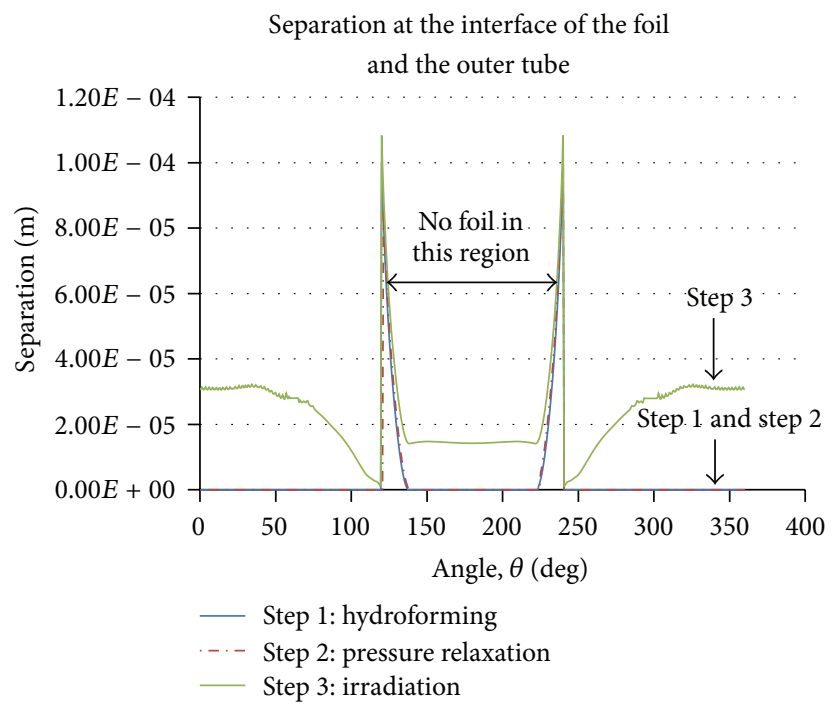

FIGURE 10: Separation at the interface of the foil and the outer tube after the various modeling steps.

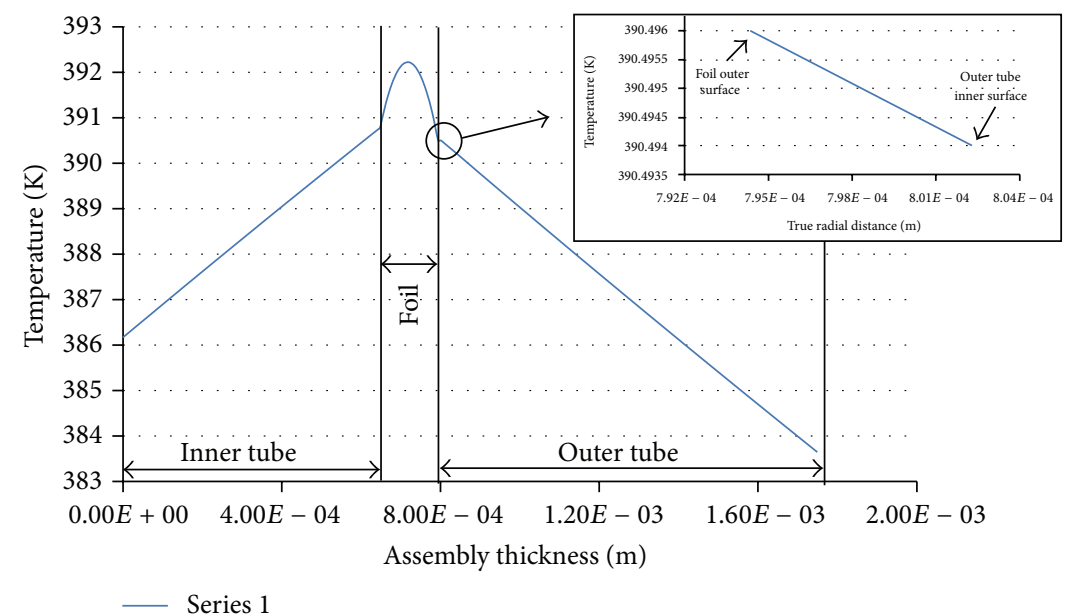

FIGURE 11: Radial temperature distribution across the inner and outer cladding.

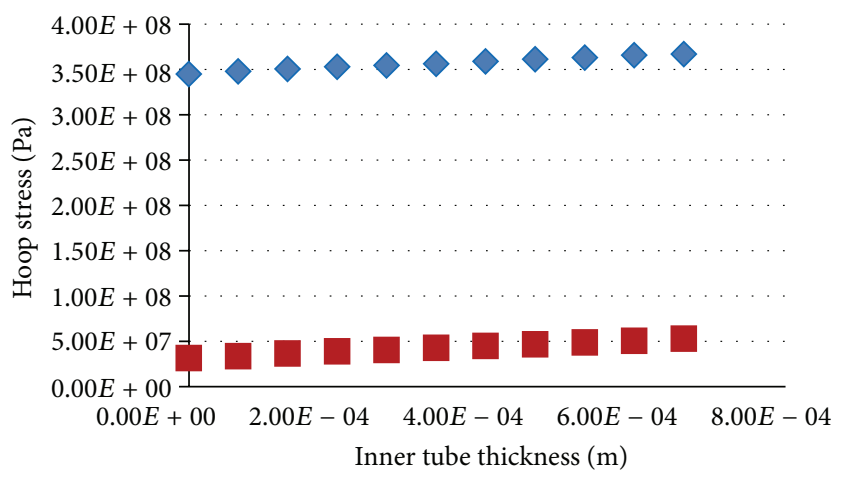

Step 1: hydroforming

Step 2: pressure relaxation

(a)

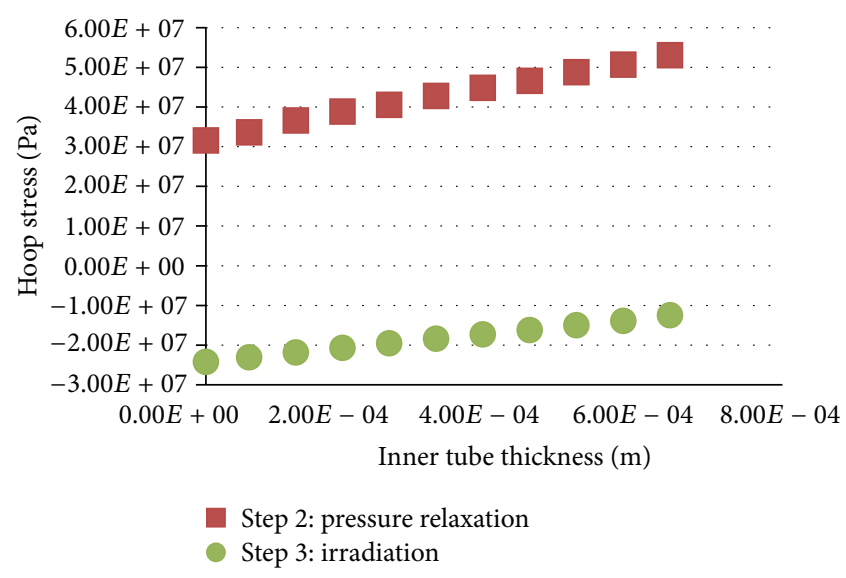

(b)

FIGURE 12: Hoop stress distribution in the inner tube through various modeling steps at $\theta=270^{\circ}$. 


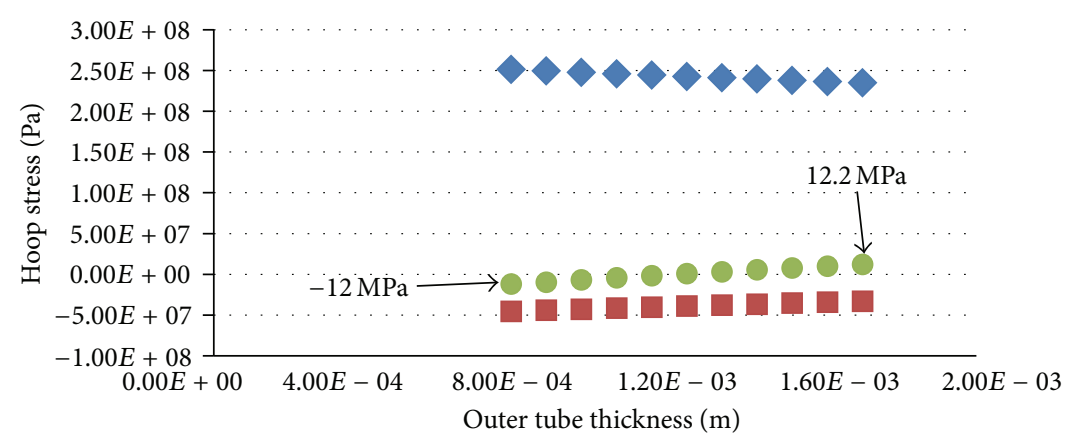

Step 1: hydroforming
Step 2: pressure relaxation
Step 3: irradiation

FIGURE 13: Hoop stress distribution in the outer tube through various modeling steps at $\theta=270^{\circ}$.

decreases from the outer surface to the inner surface for the inner tube for radially inward heat flow and from the inner surface to the outer surface for the outer tube for radially outward heat flow. Due to the separation between the foil and the outer tube, there is a small temperature drop at this interface as illustrated in Figure 11. All the modeling was done by assuming a heat generation value that corresponds to a surface heat flux of $100 \mathrm{~W} / \mathrm{cm}^{2}$. Using this value of heat flux along with the small temperature drop shown in Figure 11 results in a negligibly small value of thermal contact resistance. However, it remains to be seen if such a small value of thermal contact resistance is significant. Efforts are currently underway [10] at the University of Missouri to experimentally quantify the thermal contact resistance using surrogate foils.

Figure 12 illustrates the hoop stress across the inner tube radius for all the steps in the model. Beginning with the hydroforming step (Figure 12(a)), the hoop stress is greater on the outer surface than on the inner surface of the inner tube. As the load is removed, the resulting residual hoop stresses drop by an order of magnitude. Figure 12(b) illustrates the variation of residual hoop stresses during the pressure relaxation step and during the irradiation step. These residual hoop stresses are compressive in the inner surface, and the magnitude of compressive stress gradually decreases across the thickness. The maximum compressive stress is on the inner surface as this is where yielding begins. Previous analysis [2] has shown that for an elastic irradiation model of an annular target that begins from a zero residual stress state, the hoop stresses in the inner tube are completely compressive and increase towards the outer surface of the inner tube. This behavior can be obtained from Figure 12(b) by subtracting the residual stresses from the postirradiation hoop stresses. This would effectively give the hoop stresses in a tube for zero residual stress state. Thus the tensile residual stresses reduce the amount of postirradiation hoop stresses in the inner tube.

The hoop stresses in the outer tube through the three modeling steps have been illustrated in Figure 13. For the hydroforming process, the hoop stresses are greater on the inner surface than on the outer surface of the outer tube. The internal pressure applied during the hydroforming process causes the outer surface of the foil to be displaced towards the inner surface of the outer tube. When these interfaces meet, the inner surface of the outer tube is displaced outwards resulting in compressive stresses. The residual stresses from the assembly process are completely compressive in the outer tube with the hoop stresses being higher on the inner surface. The resulting hoop stresses from the final irradiation step are compressive on the inner surface and tensile on the outer surface. This can be attributed to radially outward heat flow through the outer tube. The outer surface of the outer tube is unrestrained and therefore free to expand. The free expansion of the outer surface results in tensile stresses being generated across the outer half of the tube, but expansion of the inner surface is resisted by the elements across the thickness of the tube.

\section{Conclusions}

The goal of this paper was to integrate the assembly process of the annular target along with the irradiation analysis to analyze the behavior of the target and assess the effect of residual stresses. A three-step elastoplastic model was built using the commercial finite element code Abaqus FEA [7]. The first analysis step simulated the hydroforming process using an internal pressure of $36.4 \mathrm{MPa}$, and this was followed by a pressure relaxation step to simulate the recovery. The third step simulated the irradiation process by including the residual stresses from the previous step.

The results from the analysis show that the applied internal pressure is adequate to induce enough plastic deformation to maintain the bond at the interface of the foil and the outer tube. The residual stresses from the assembly process tend to negate and decrease the hoop stresses in the inner and outer tubes at the end of the irradiation step. This is favorable from a material standpoint as the inner and outer tubes are unlikely to fail under the applied heat generation of $1.6 \times 10^{10} \mathrm{~W} / \mathrm{m}^{3}$. This corresponds to a heat flux of $100 \mathrm{~W} / \mathrm{cm}^{2}$ incident on the outer surface of the inner tube and the inner surface of the outer tube. The postirradiation compressive hoop stresses 
in the inner tube are greater than the stresses in the outer tube, which move from being compressive to tensile across the thickness. Hence, the inner tube is likely to dictate the failure of the target.

\section{Acknowledgments}

The authors would like to thank Charlie Allen at the University of Missouri Research Reactor (MURR), Dr. Sherif ElGizawy at the University of Missouri, Dr. George Vandegrift at Argonne National Laboratory, and Lloyd Jollay and John Creasy at Y-12 National Security Complex for supporting this activity.

\section{References}

[1] K. K. Turner, G. L. Solbrekken, and C. W. Allen, "Thermalmechanical response of non-uniformly heated nominally flat and curved LEU foil based target," in Proceedings of the ASME International Mechanical Engineering Congress \& Exposition, Paper IMECE2012-88939, Houston, Tex, USA, November 2012.

[2] S. G. Govindarajan, G. L. Solbrekken, and C. W. Allen, "Thermal-mechanical analysis of a low-enriched uranium foil based annular target for the production of molybdenum-99," in Proceedings of the ASME International Mechanical Engineering Congress and Exposition, Paper IMECE2012-86921, Houston, Tex, USA, November 2012.

[3] US. Department of Energy, DOE Fundamentals HandbookMaterial Science, vol. 2 of Claddings and Reflectors, US. Department of Energy, Washington, DC, USA, 2010.

[4] A. S. El-Gizawy, J. K. Berlin, and B. S. Graybill, "Robust design of assembly process of targets carrying LEU foils for production of Mo-99," in Proceedings of the ANS Winter Meeting and Nuclear Technology Expo, Technical Conference Proceedings: The Status of Global Nuclear Deployment, Washington, DC, USA, November 2011.

[5] C. V. Madhusudana, "Thermal conductance of cylindrical joints," International Journal of Heat and Mass Transfer, vol. 42, no. 7, pp. 1273-1287, 1999.

[6] A. Mutalib, B. Purwadi, H. G. Adang et al., "Full scale demonstration of the cintichem process for the production of molybdenum-99 using a low enriched uranium target," in Proceedings of the International Meeting on Reduced Enrichment for Research and Test Reactors, Sao Paulo, Brazil, October 1998.

[7] “Abaqus FEA," Version 6.12-2, D S Simulia, DassaultSystemes, 2002-2013.

[8] R. K. S. Racha, Damage characterization of four wrought aluminum alloys [M.S. thesis], Tennessee Technological University, 2008.

[9] G. R. Caskey Jr., "Memo to P.H. Permar," Technical Division Savannah River Laboratory, Aiken, SC, USA, 1965.

[10] P. F. Makarewicz, S. G. Govindarajan, and G. L. Solbrekken, "Experimental testing of annular target surrogates for the production of molybdenum-99," in Proceedings of the ASME International Mechanical Engineering Congress \& Exposition, Paper IMECE2012-87783, Houston, Tex, USA, November 2012. 


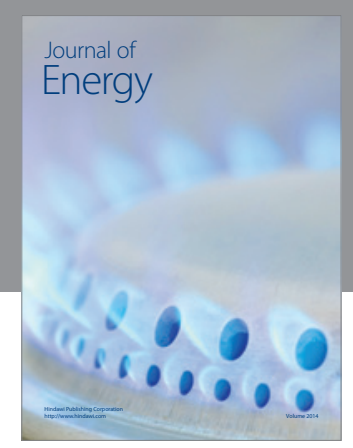

Journal of

Industrial Engineering
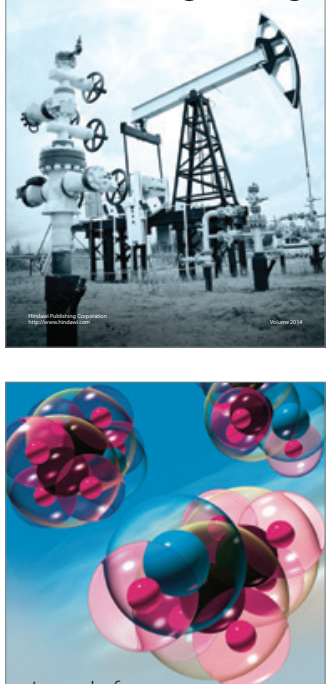

Fuels
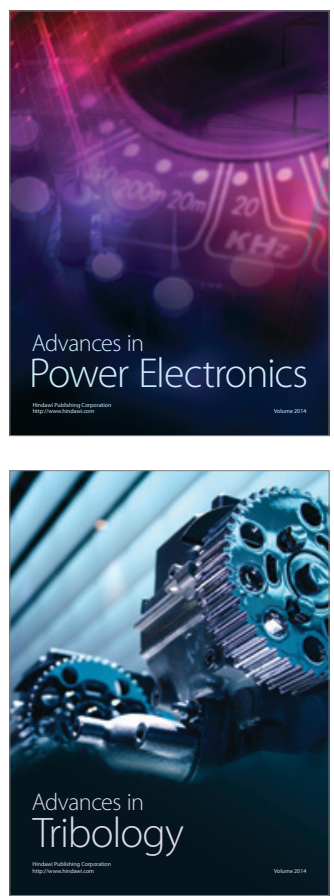

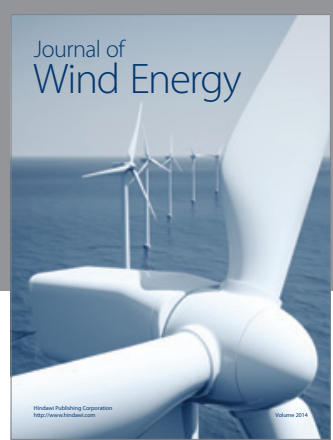

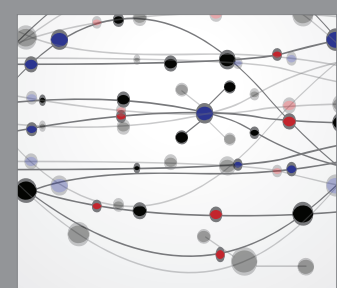

The Scientific World Journal

Submit your manuscripts at http://www.hindawi.com

Journal of

Structures
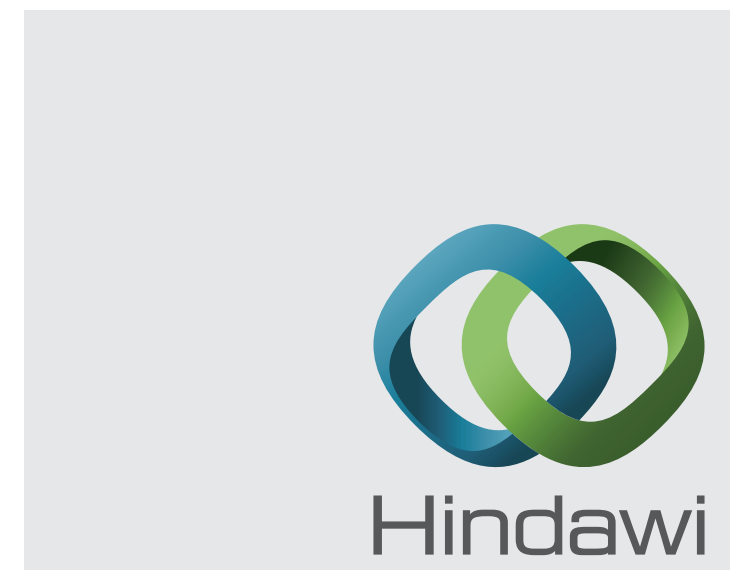

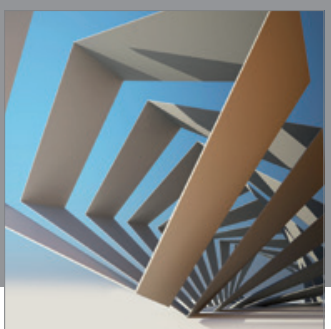

Rotating

Machinery
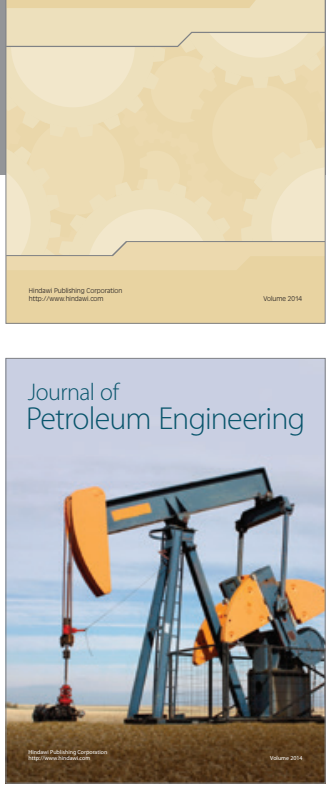

Journal of

Solar Energy
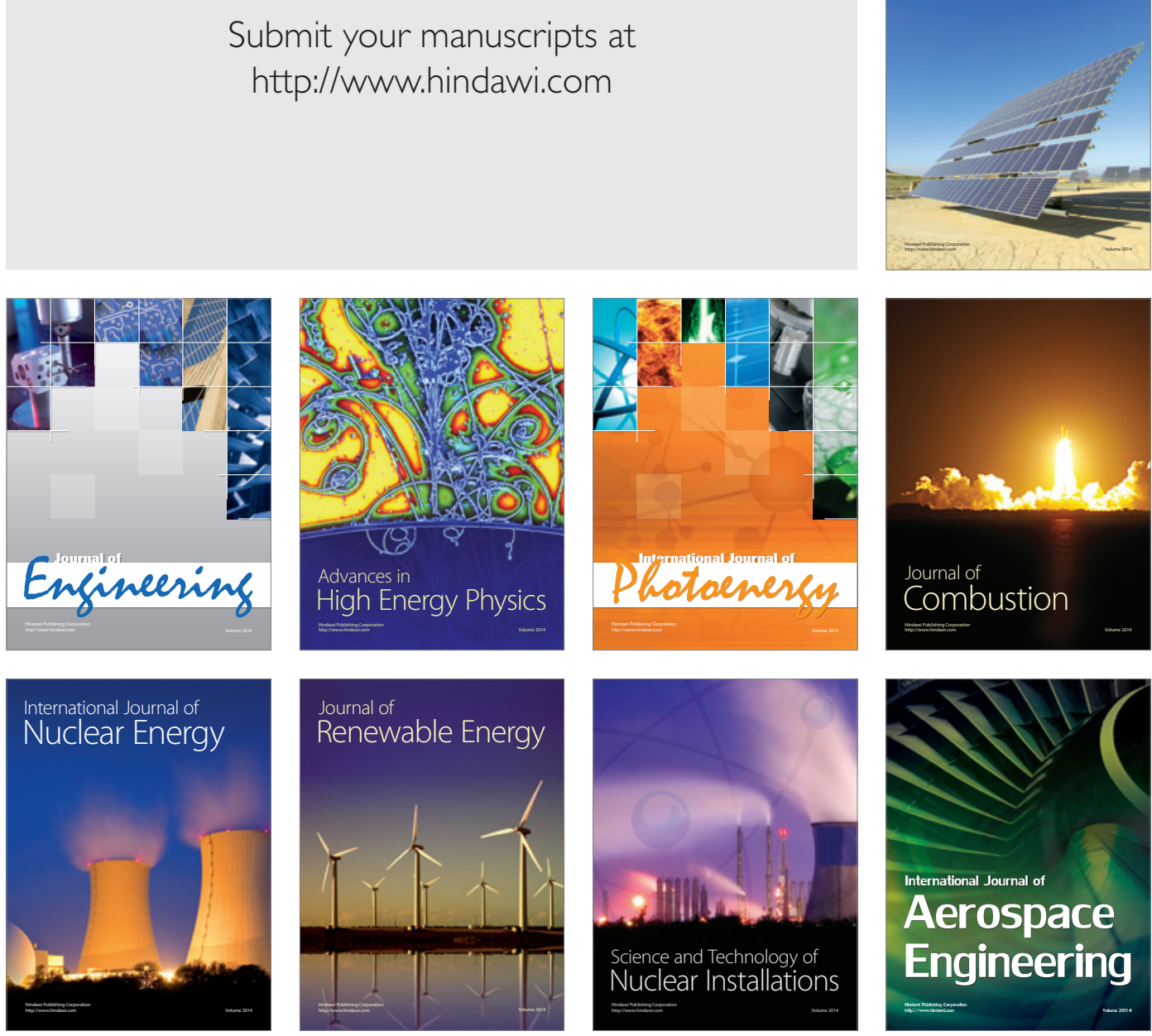